\title{
Urinary Tract Reconstruction: Applied Urodynamics
}

\author{
D. Key, J. Wan, R. Grainger, T. McDermott, E.J. McGuire, and D.A. Bloom \\ Section of Urology, Department of Surgery, University of Michigan Medical Center, \\ Ann Arbor, Michigan
}

\begin{abstract}
Sixty-four patients underwent urinary reconstruction guided by urodynamic investigation. Twenty-eight patients had myelodysplasia (MM) and 26 had spinal cord injuries (SCI). Operative outcomes were assessed by repetitive urodynamic testing.

Bladder reservoir function and detrusor contractile activity were correctly assessed in all 64 patients. Operative creation of a more adequate reservoir was required in 58 patients.

Assessment of urethral continence function was inaccurate in six instances wherein we judged urethral sphincter function adequate when, in fact, it was not. Ureteral function was judged radiographically or by furosimide renography, or Whitaker perfusion testing. In the two instances where ureteral function was in doubt, it made no difference in outcome. There was a striking resolution of ureteral radiographic abnormalities after reconstruction which we attribute to the low-pressure reservoir.
\end{abstract}

Key words: myelodysplasia, undiversion, spinal cord injury, upper tract disease, urethral function, evaluation of, bladder function, evaluation of, augmentation cystoplasty, continent stoma, neourethra

\section{INTRODUCTION}

One way, and perhaps the only accurate way, to evaluate whether urodynamics testing is useful and precise is to determine whether treatment predicated on urodynamic testing actually works [McGuire and Savastano, 1984a,b]. During the past 6 years, we have reconstructed the urinary tract in 64 patients, in an effort to achieve continence, and a low-pressure reservoir. All of these patients were studied radiographically and urodynamically pre-operatively and that data used to plan the operative procedure. Postoperatively, all patients were studied radiographically and urodynamically at regular intervals to determine pressure volume curves, the presence of vesico ureteral reflux, and continence, as well as to assess the effect of the operative procedure on renal and ureteral function. We assumed that a low-pressure reservoir would protect upper urinary tract function.

Received for publication November 6, 1989; acceptcd March 20, 1990.

Address reprint requests to E. J. McGuire, M.D., Section of Urology, 2916TC/Box 0330, 1500 E. Medical Center Drive, Ann Arbor, MI 48109. 


\section{PATIENT POPULATION}

Twenty-eight patients with myelodsyplasia, 26 patients with spinal cord injury, and 10 patients with a variety of other disease processes adversely affecting lower urinary tract function comprised the study group. Of these, 26 patients had an ileal or sigmoid loop, or bilateral cutaneous ureterostomy. Twenty-two were managed by chronic Foley or suprapubic catheter drainage. Of the group managed by catheters, 7 had urethrocutaneous fistulas and nine were continuously incontinent. Four patients had a vesicostomy and all of these were incontinent per urethram. Twelve patients were incontinent despite intermittent catheterization and drugs, and were in diapers, or had resorted to short-term catheter drainage. Thirty-eight patients had definable upper urinary tract disease associated with renal stone formation, x-ray evidence of pyelonephritis with clubbing, and renal parenchymal loss, loss of a renal unit, hydoureter, and/or renal failure.

\section{METHODS}

Urodynamic evaluation consisted of combined fluoroscopy and pressure measurements utilizing a Bard ${ }^{\mathrm{R}}$ triple lumen urodynamic catheter. Assessment of urethral continence function consisted of measurement of urethral closing pressure under fluoroscopic control - with particular attention to the proximal urethra. The urethra was observed fluoroscopically during coughing, straining, and the valsalva maneuver with the bladder filled to half capacity. Bladder function was evaluated by filling with $20 \%$ iodinated contrast material while intravesical and intraurethral pressures were constantly recorded. Urethral pressures were measured from within the "high pressure zone." The pressure volume curve of the bladder was determined until 40 $\mathrm{cm} / \mathrm{H}_{2} \mathrm{O}$ was reached, or a reflex bladder contraction occurred, or a 400-600 volume was reached depending on the patient's age.

Ureteral function was evaluated radiographically by intravenous urography. If ureteral dilation was present, direct fluoroscopic observation of peristalsis was performed, or a dynamic renogram was obtained, or a direct perfusion pressure flow study was performed (Fig. 1A,B).

\section{RESULTS \\ Myelodysplasia}

Clinical status. The myelodysplatic patient group included 15 patients with supravesical diversion. Of these 15 , five had a significant decrease in renal function, 13 had radiographic evidence of renal parenchymal damage related to pyelonephritis (Fig. 2), 5 had renal calculi, 7 had bilateral or unilateral hydroureter, 1 had stomal stenosis, and 1 had a uretero-ileal anastomotic stricture. Percutaneous nephrostomy was required in seven of these patients for management of upper tract problems prior to evaluation for undiversion. Four patients had vesicostomies, one of these had a unilateral staghorn calculus with renal damage, and all were incontinent per urethra. Two patients had suprapubic tubes, both were incontinent, and one of these had a urethral perineal fistula with a large perineal ulceration with active osteomyelitis. Six patients were incontinent and in diapers and one had a Foley catheter. 

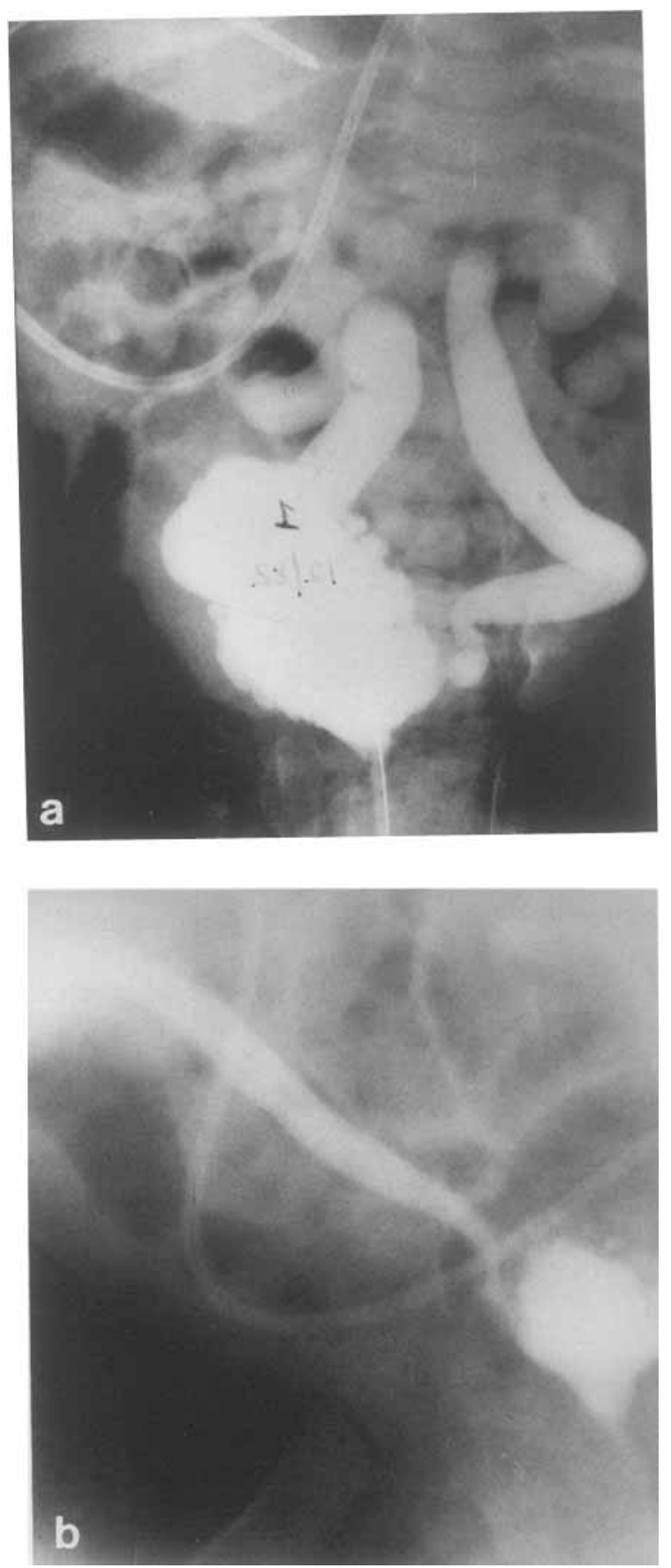

Fig. 1. A: Massive bilateral collecting system and ureteral dilation in a 2 year-old child with myelodysplasia. B: Whitaker perfusion spot film. The ureter showed active peristalsis and tolerated perfusion at $10 \mathrm{ml} / \mathrm{min}$ with the bladder emptied by a Foley catheter. At a $30 \mathrm{ml}$ bladder volume, the ureteral perfusion pressure rose steeply and continued to rise. While the ureter is dilated, it is not obstructed. The problem is poor bladder compliance. 

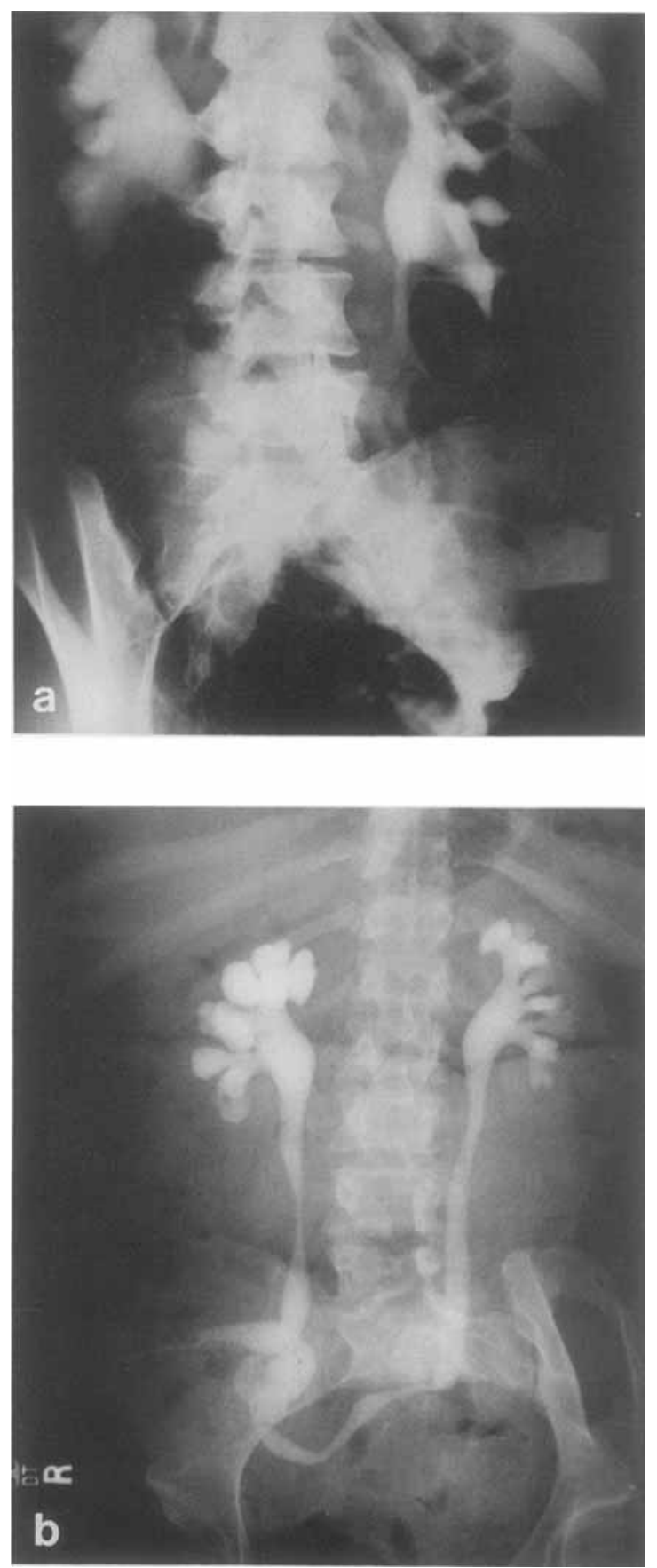

Fig. 2. A: Intraveneous urogram from a 15 year-old female with bilateral end ureterostomies since age of $11 / 2$ years. There are bilateral calyceal changes, renal parenchymal loss, and unilateral dilation of the collecting system, renal pelvis, and ureter on the right. B: Retrograde ileal loop injection study shows pyelonephritic changes in both kidneys and moderate ureteral dilation. This patient had a right lower pole calculus and bilateral renal parenchymal scarring. 
TABLE I. Urodynamic Findings

\begin{tabular}{lrrr}
\hline & MM & SCI & Other \\
\hline Areflex bladder poor compliance & 25 & 0 & $5^{\mathbf{a}}$ \\
Areflex bladder acceptable compliance & 0 & 6 & 0 \\
Reflex bladder - dyssynergic sphincter & 2 & 20 & 0 \\
Reflex bladder - normal sphincter & 0 & 0 & 1 \\
No bladder & 1 & 0 & 4 \\
Normal urethra & 2 & 15 & 5 \\
"Acceptable" urethral function & 8 & 0 & \\
No urethral function & 18 & 11 & $3^{\text {b }}$ \\
\hline
\end{tabular}

ane improved after cycle filling.

bone of these three had had a cystectomy.

Urodynamic findings. Of 28 myelodysplastic patients, 1 had no bladder or urethra, 2 had reflex vesical function with a dyssynergic external sphincter, and 25 had an areflexic bladder with diminished compliance defined as a bladder which tolerated less than $300 \mathrm{ml}$ in adults, or $100 \mathrm{ml}$ in children at a pressure of $40 \mathrm{~cm} / \mathrm{H}_{2} \mathrm{O}$. Of 27 evaluable urethras, two were normal, and eight showed stress competence despite poor proximal urethral closure (Table I). The remaining 18 were both open from the vesical outlet to the high-pressure zone radiographically and urodynamically and stress incompetent. In the latter group, in the 10 instances where this was specifically measured, the abdominal pressure generated by a valsalva maneuver required to force urine across the urethra ranged from 12 to $28 \mathrm{~cm} / \mathrm{H}_{2} \mathrm{O}$. (A normal urethra will tolerate, without leakage, abdominal pressures in excess of $150 \mathrm{~cm} / \mathrm{H}_{2} \mathrm{O}$.) (Table I).

\section{Spinal Cord Injury}

Clinical status. Of 26 spinal cord injured patients, 20 were managed by chronic suprapubic or Foley urethral catheter drainage. Six of these had urethrocutaneous fistulas, draining in four into large perineal ulcers with active osteomyelitis. (Fig. 3). In one female patient, the anterior urethra was eroded with associated osteomyelitis of the pubis, and in another the entire posterior urethra was eroded into the vagina. Of the group managed by catheters, nine had radiographic evidence of renal parenchymal loss, and three had renal calculi. Two patients had ileal loop diversions and one of these had bilateral hydroureter and unilateral renal stones. The remaining four patients were wet despite intermittent catheterization and anticholinergic agents. None of these four patients had upper tract abnormalities.

Urodynamic findings. The majority of patients (21) showed a reflex bladder with detrusor sphincter dyssynergia. (Table 1). In five of these, compliance was also poor with capacities ranging from $30 \mathrm{ml}$ to $80 \mathrm{ml}$ at pressures of $40 \mathrm{~cm} / \mathrm{H}_{2} \mathrm{O}$. In two of these five, chronic daily autonomic dysreflexia was a problem. All of this group of five had long-term suprapubic catheters.

Six patients demonstrated detrusor areflexia, without a significant decrease in storage capacity defined by pressure, but all six had either a urethrocutancous fistula or a totally nonfunctional urethral sphincter associated with long-term Foley catheter drainage. An additional three patients also managed by Foley or suprapubic catheter drainage had a nonfunctional urethral continence mechanism. 


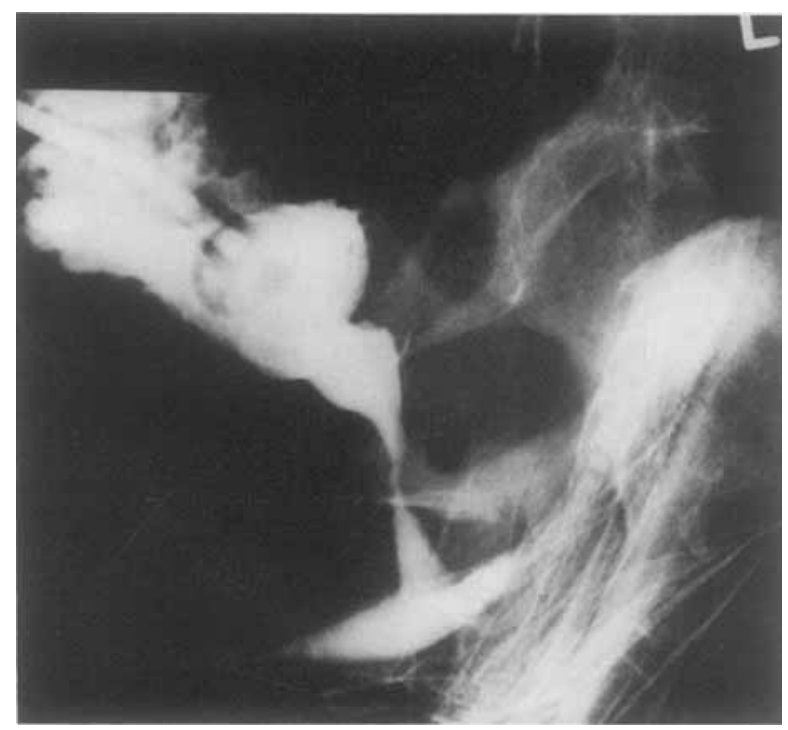

Fig. 3. Cystourethrography via a suprapubic catheter in a 28 year-old paraplegic. The urethra has no closing function and there is a very large urethra cutaneous fistula draining into a perineal ulcer.

\section{Non-Neurogenic Group}

Clinical status. The remaining 10 patients had a variety of underlying disease processes including, in 3 women, recurrent childhood infections and vesicoureteral reflux finally managed by ileal loop diversion (1) or cutaneous ureterostomy (2) (Table I). There were 4 patients with bladder extrophy, 3 managed by ileal loop diversion and 1 by diapers, and 1 patient with an ileal loop after cystectomy for rhabdomyosarcoma. Of these 10, 4 had no bladder, 7 had bilateral ureteral dilation, 3 had already lost one kidney due to infection or obstruction, and 9 had evidence of pyelonephritic scarring, intrarenal collecting system abnormalities, and renal stones. Only one patient in this group had a normal upper urinary tract.

Urodynamic findings. Of these 10, 4 had no bladder, 5 had an areflex bladder with poor compliance, and 1 had a reflex bladder with a normal urethral sphincter. One of 4 patients had an incompetent urethra after cystectomy. The others had no urethra or an ipiopradiac urethra.

\section{Reconstruction}

Undiversion. Twenty-seven patients underwent urinary undiversion (Table II). Twenty-five of these had either no bladder (five) or an inadequate bladder (20). Fifteen were found to have no urethra (four) or a urethra which was inadequate for continence. One bladder was thought to be normal, another an adequate areflexic reservoir. Urethral function in 11 patients was thought to be adequate. Simple undiversions were performed in two patients with bladders and urethras judged to be "normal" or acceptable. Seven patients had a neobladder constructed, six with a continent abdominal stoma; in onc instance, the ileocecal reservoir was sutured to a urethral stump in conjunction with a pubovaginal sling procedure. New reservoirs were constructed for five patients with no natural bladder, and in two instances because the natural bladder and urethra was judged not salvagable. 
TABLE II. Undiversion-Operative Procedures and Results

\begin{tabular}{lccll}
\hline & $\mathrm{n}$ & Dry & Wet & Final outcome \\
\hline $\begin{array}{l}\text { Neo-reservoir }(\mathrm{n}=7) \\
\quad \text { Continent stoma }\end{array}$ & 6 & 5 & 1 & Unchanged \\
$\quad \begin{array}{l}\text { To urethra } \\
\text { Augmentation }(\mathrm{n}=18)\end{array}$ & 1 & $\mathbf{1}$ & 0 & \\
$\quad \begin{array}{l}\text { With urethral procedure } \\
\quad \text { Urethral procedure and }\end{array}$ & 5 & 5 & 0 & \\
$\quad$ continent stoma & 3 & 3 & 0 & \\
$\quad \begin{array}{l}\text { Augmentation alone } \\
\text { Simple undiversion }\end{array}$ & 10 & 5 & 5 & (5 dry after subsequent sling) \\
\hline
\end{tabular}

An augmentation cystoplasty with a urethral procedure (pubovaginal sling or puboprostatic sling) was performed in eight patients, three of whom also had a continent abdominal stoma constructed because they could not perform urethral catheterization. Augmentation cystoplasty alone, with no urethral procedure, was performed in 11 patients, all of whom were thought to show adequate urethral closing function. Overall outcome with respect to achievement of continence is shown in Table II.

Without undiversion-operative procedures. Of 37 patients with catheters, suprapubic tubes, vesicostomies, or failure of intermittent self-catheterization, one underwent cystectomy and neoreservoir construction for bladder carcinoma discovered during evaluation for incontinence despite a Foley and suprapubic tube. Thirtytwo patients had an augmentation cystoplasty. In 23 patients, the urethra was judged to be inadequate. In 10 of these the augmentation was combined with a urethral continence procedure (9 slings and 1 AMS sphincter). In 13, a urethral procedure (sling 4, closure 9) was combined with continent abdominal stoma construction to permit intermitent catheterization in 4 instances, and in 9 to obviate urethral damage which was judged impossible to correct other than by transection and closure. Nine patients had, by urodynamic testing, good urethral function and had only an augmentation cystoplasty. Results with respect to continence are given in Table III.

Four remaining patients were all spinal-cord-injured individuals. Two achieved adequate reservoir function with intermittent catheterization, and were judged to have normal urethral function. Both underwent continent vesicostomy and both are dry and able to catheterize themselves. The two other patients, high quadraplegics with suprapubic tubes, had constant urethral leakage, complicated by autonomic dysreflexia. Both underwent urethral closure and ileovesicostomy. Both are dry with an appliance and neither has autonomic dysreflexia.

\section{Outcome-Reservoir Function}

Measured reservoir function defined by the pressure attained at maximum volumes recovered by intermittent catheterization in 58 patients and/or at the time of leakage in four patients improved to a mean value of $24 \mathrm{~cm} / \mathrm{H}_{2} \mathrm{O}$. Of the entire group, six continue to show vesicourcteral reflux at high reservoir volumes; one patient continues to have occasional urethral incontinence related to low pressure $(20-24$ $\mathrm{cm} / \mathrm{H}_{2} \mathrm{O}$ ) reservoir contractions. 
TABLE III. Reconstruction Without Undiversion-Results

\begin{tabular}{|c|c|c|c|c|}
\hline & $\mathrm{n}$ & Dry & Wet & Reason \\
\hline Augmentation alone & 9 & 8 & 1 & Reservoir reflex contraction \\
\hline $\begin{array}{l}\text { Augmentation and urethral } \\
\text { procedure }\end{array}$ & 11 & 8 & 3 & $\begin{array}{l}\text { Inadequate sling salvaged } \\
\text { with collagen }\end{array}$ \\
\hline $\begin{array}{l}\text { Augmentation and urethral } \\
\text { closure, continent stoma }\end{array}$ & 13 & 12 & 1 & Valve failure \\
\hline Free reservoir & 1 & 0 & 1 & Valve failure \\
\hline Total & 33 & 27 & $6^{\mathrm{b}}$ & \\
\hline
\end{tabular}

a Two patients had a free draining conduit from the reservoir to the skin.

${ }^{b}$ Corrected in three of six with subsequent procedure.

\section{Complications}

Two patients developed a spontaneous reservoir perforation which required drainage and repair. Two patients developed ureteral intestinal anastomostic strictures which required reimplantation. Four patients developed reservoir calculi requiring endoscopic removal.

\section{Upper Tract Function}

Of 19 patients with vesicoureteral reflux, three continue to reflux. Eight patients with unilateral (three) or bilateral renal stones have formed no new stones after treatment and urinary reconstruction. Eighteen patients with radiographic evidence of renal parenchymal loss and intrarenal collecting system changes consistent with pyelonephritis have remained free of recurrent clinical pyelonephritis, and the radiographic findings are stable (Fig. 4A,B). Fourteen patients with recurrent sepsis due to urinary infection or urinary contamination of perineal ulceration with osteomyelitis have been symptom free, and all of the ulcers have been surgically closed successfully. Of 12 patients with hydroureter, all radiographic changes have completely resolved. Over a mean 39 months follow-up period, 11 patients have been readmitted, 2 for uretero-ileal stenosis, 3 for collagen injection, 2 for spontaneous perforation of the reservoir, and 2 for reservoir stone removal. Prior to reconstruction, these 64 patients experienced, on the average, two hospital admissions per year for urological conditions.

\section{DISCUSSION}

The overall freedom in this patient group from upper tract infection, stone formation, sepsis, and reflux and hydroureter does not prove that a low-pressure reservoir is the sole reason for the improved overall status but it strongly suggests that that is the case. Certainly resolution of recurrent stone formation, of sepsis associated with osteomyelitis, and of hydro-ureternephrosis is directly related to achievement of continence and low-pressure reservoir [McGuire and Savastano, 1983]. Virtually all such patients are intermittently or continuously bacteriuric - as they were prior to undiversion, and the only consistent measurable change brought about by the reconstructive procedure is a low-pressure urinary reservoir. It seems likely that this protects the ureters and ultimately the kidneys. Three patients who required transplan- 

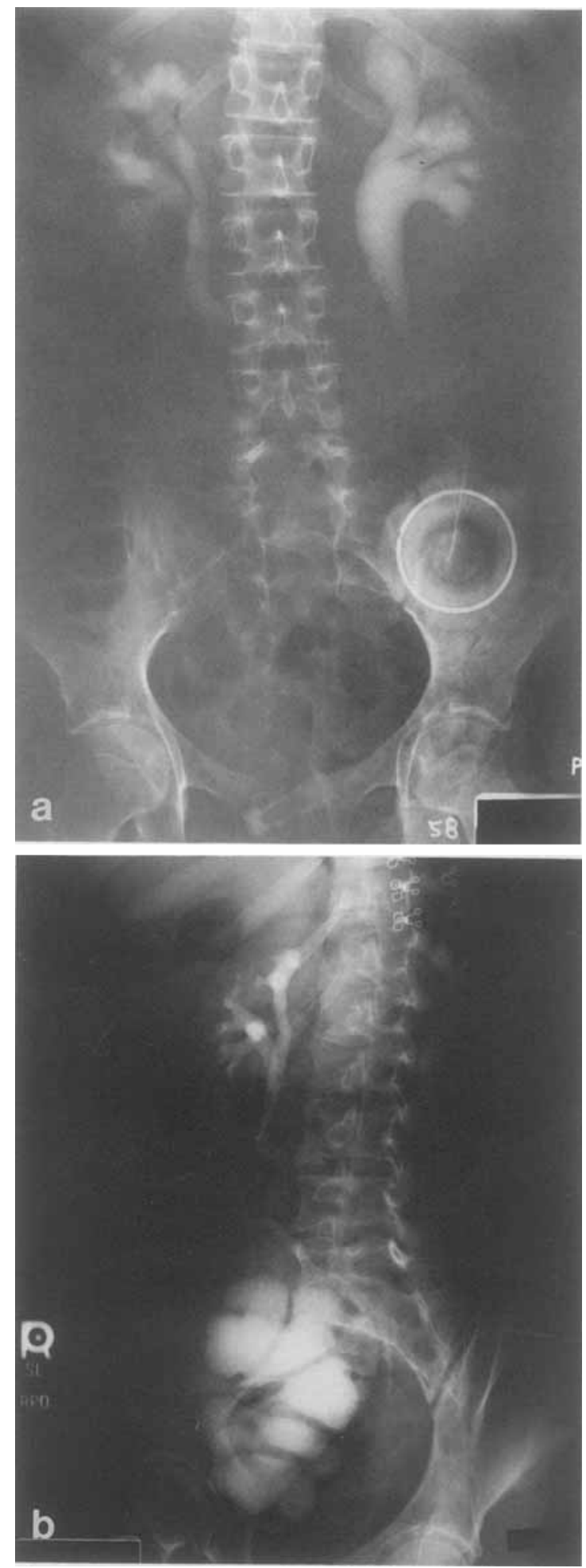

Fig. 4. A: Preoperative appearance of the upper urinary tract in a young woman with bilateral cutaneous ureterostomies. B: Postoperative situation with a large-volume low-pressure reservoir. 
tation into reconstructed urinary tracts have done remarkably well following that procedure.

Even though some ureters were large, we judged peristalsis to be present and adequate in all but two cases. In the two instances where we were not convinced about ureteral function, remplantation into a low-pressure reservoir did not impair ureteral or renal function.

Urodynamic testing (or the interpretation of that testing) for urethral competence was not completely accurate. We thought on the basis of that testing that 22 patients had sufficient urethral function for continence. That was in error in five instances, and a further urethral procedure was required. All of these patients showed poor urethral (proximal) closure, but stress testing did not result in leakage. We would now rely on valsalva leak point pressures - and the resting fluoroscopic picture-and disregard stress testing results in planning operative procedures.

Even when we knew the urethra was not adequate, we were unable to adequately repair or reconstruct it in five of 31 cases, all of whom required a second procedure before urinary continence was achieved.

Continent abdominal stoma construction, as part of either an augmentation cystoplasty or a bladder replacement procedure, was unsuccessful in four of 26 cases. In three of these instances, the valve leaked at low pressures, but did not leak at higher pressures, necessitating both an appliance and intermittent catheterization. In the other patient with valve failure, the ileal segment could not be catheterized easily and was revised to a drainage conduit.

The problem of reservoir calculi seems to be related to mucous production, incomplete emptying, and in some cases, to surgical staples used for the bowel resection which we now isolate from the reservoir. Periodic (6 months) flexible endoscopy permits early recognition - and stone extraction under local anesthesia, which we now do routinely.

We were thus, with practice, able to identify which urethra required a reconstructive procedure, even if we were unable to always achieve what was needed surgically. In four instances, we correctly thought bladder reservoir function was adequate. We made an attempt to estimate ureteral function, particularly in those situations where the ureter was chronically dilated. Despite our concern about the ability of the ureter to tolerate an undiversion, no problems occurred which could be attributed to the operative procedure. These findings suggest that even a widely dilated, poorly contractile ureter will tolerate undiversion into a low-pressure reservoir-or that our current methods to estimate ureteral function are not very accurate.

Since 1981, our ideas about undiversion and reconstruction have changed in that it is now clear that a low-pressure reservoir, achieved with bowel segments, is essential for a good outcome. Otherwise, the recommendations in the report of a workshop held at the University of New Mexico in 1981 are valid and useful [Borden et al., 1981].

\section{REFERENCES}

Borden TA, McGuire EJ, Woodside JR, Allen TD, Bauer SB, Firlit CF, Gonzales ET, Kaplan WE, King LR, Klauber GT, Perlmutter AD, Thornbury FR, Weiss RM (1981): Urinary undiversion in patients with myelodysplasia and neurogenic bladder dysfunction: Report of a workshop. Urology 18:223.

McGuire EJ, Savastano JA (1983): Long term follow up of spinal cord injury patients managed by intermittent catheterization. J Urol 129:102. 
McGuire EJ, Savastano JA (1984a): Urodynamic findings and clinical status following vesical dennervation procedures for control of incontinence. J Urol 132:87.

McGuire EJ, Savastano JA (1984b): Urodynamic findings and long term outcome of management of patients with multiple sclerosis induced loqwer urinary tract dysfunction. J Urol 132:713. 